\title{
Research Article \\ Effect of the Amount of Mineral Powder on the Ultraviolet Aging Properties of Asphalt
}

\author{
Xiangbing Xie, ${ }^{1}$ Shenjia Tong, ${ }^{1}$ Yabi Ding, ${ }^{1}$ Hongni Liu, ${ }^{2}$ and Linyuan Liang ${ }^{1}$ \\ ${ }^{1}$ School of Civil Engineering, Xian University of Architecture and Technology, Xian, Shaanxi 710055, China \\ ${ }^{2}$ Xian Modern Chemistry Research Institute, Xian, Shaanxi 710065, China \\ Correspondence should be addressed to Shenjia Tong; 2583694966@qq.com
}

Received 1 April 2016; Revised 31 July 2016; Accepted 18 October 2016

Academic Editor: Ying Li

Copyright (c) 2016 Xiangbing Xie et al. This is an open access article distributed under the Creative Commons Attribution License, which permits unrestricted use, distribution, and reproduction in any medium, provided the original work is properly cited.

\begin{abstract}
Mortar has an important influence on the viscosity and durability of a mixture. The effects of the amount of mineral powder in asphalt mortar on the ultraviolet (UV) aging properties of asphalt were investigated by a Fourier transform infrared spectrum (FTIR), gel permeation chromatography (GPC), and dynamic shear rheometer (DSR). The FTIR results show that the UV-resistant aging ability of asphalt mortar was superior to asphalt and that the carbonyl indices of the SBS- (styrene-butadiene-styrene-) asphalt mortar and matrix asphalt mortar were more significant. The GPC results show that the molecular weight distribution coefficient $\left(M_{w} / M_{n}\right)$ of the SBS-asphalt-filler mastic is 1.0 and that of the matrix asphalt-filler mastic is 1.2, which is the largest. The macroproperty is the most stable. The DSR results show that the matrix asphalt-filler mastic ranging from 1.0 to 1.2 and the SBS-modified asphalt-filler mastic ranging from 0.8 to 1.0 show the best UV aging resistance. Therefore, the effects of the amount of mineral powder cannot be ignored, suggesting that the best mass ratio of the matrix asphalt mortar is 1.2 and that of the SBS-modified asphalt mortar is 1.0 during the UV aging process.
\end{abstract}

\section{Introduction}

Many researchers believe that coarse aggregates in asphalt mixtures are coated by a blend of asphalt binder and mineral powder rather than pure bitumen [1-5]. The characteristics of asphalt mortar have a decisive role on the durability of asphalt pavement. Therefore, researchers have done various studies on asphalt mortar. For example, Tan et al. [6] studied the effects of filler-bitumen (by mass) on the high temperature and low temperature performance of asphalt mortar through DSR test and bending beam rheometer (BBR) test. The results indicated that the rheological behavior of asphalt mortar followed the exponent function model and calculated the inflection point of the curve model to determine the best ratio in the range of 0.9-1.4. The Chinese JTG F40-2004 requires that the filler-bitumen ratio should meet requirements of $0.6-$ 1.6; in particular the dense-graded asphalt mixtures in the nominal maximum aggregate size $(13.2-19 \mathrm{~mm})$ should be controlled within the optimum range of 0.8-1.2 [7]. Wang et al. [8] studied the effect of mineral powder on the aging properties of asphalt. The results showed that the addition of the mineral powder could relieve the aging degree of asphalt when the mass ratio of mineral powder to asphalt was less than 1.5. Brown et al. [9] thought that the filler-bitumen ratio should be restricted among 0.8-1.6 for the coarse-graded mixture under the Superpave restricted zone in order to improve high temperature stability.

The component and chemical structure of asphalt can be changed owing to aging in the process of constructing and exposure in the field, further influencing its rheological properties [10]. And the aging of asphalt can be separated into two main different types [11]. One is thermal aging and the other is UV radiation aging. These related research results of asphalt aging have been a lot. For example, Kim and Burati [12] and Al-Abdul Wahhab et al. [13] evaluated molecular size by analyzing the GPC chromatographic profiles of the asphalt based on the rolling thin film oven (RTFOT) aging. Their results indicated that the large molecular size (LMS) increased significantly, the medium molecules size (MMS) firstly increased and then decreased, and the small molecules size (SMS) 
TABLE 1: Physical properties of base asphalt and modified asphalt.

\begin{tabular}{lcc}
\hline Property & $\begin{array}{c}\text { SBS modified } \\
\text { asphalt }\end{array}$ & SK-90 \\
\hline $\begin{array}{l}\text { Density }\left(15^{\circ} \mathrm{C}\right) /\left(\mathrm{g} / \mathrm{cm}^{3}\right) \\
\text { Penetration }\left(25^{\circ} \mathrm{C}, 100 \mathrm{~g},\right.\end{array}$ & 1.032 & 1.035 \\
$5 \mathrm{~s}) /(0.1 \mathrm{~mm})$ & 73.1 & 90 \\
Softening point $\mathrm{T}_{\mathrm{R} \& \mathrm{~B}} /{ }^{\circ} \mathrm{C}$ & 76 & 46 \\
Ductility $\left(15^{\circ} \mathrm{C}, 5 \mathrm{~cm} / \mathrm{min}\right) / \mathrm{cm}$ & 41.9 & $>100$ \\
Penetration index $(\mathrm{PI})$ & 0.037 & -1.37 \\
After TFOT $163^{\circ} \mathrm{C}, 85 \mathrm{~min}$ & & \\
$\quad$ Mass loss $/ \%$ & -0.11 & 0.13 \\
$\quad$ Penetration $\mathrm{ratio}$ of $25^{\circ} \mathrm{C} / \%$ & 86 & 60.0 \\
$\quad$ Ductility $\left(15^{\circ} \mathrm{C}, 5 \mathrm{~cm} / \mathrm{min}\right) / \mathrm{cm}$ & 27.5 & 15.8 \\
\hline
\end{tabular}

TABLE 2: Particle size distribution of mineral filler.

\begin{tabular}{lcccccc}
\hline Particle size $(\mu \mathrm{m})$ & 63.42 & 30.70 & 14.26 & 6.76 & 2.43 & 1.26 \\
\hline Percentage mass $(\%)$ & 100 & 91.3 & 72.2 & 47.0 & 21.43 & 12.37 \\
\hline
\end{tabular}

decreased obviously. Wu et al. [14] and Durrieu et al. [15] pointed out that the UV effect on the surface aging of the asphalt pavement could be far greater than the pressure aging vessel (PAV) which simulated the long-term aging. Zeng et al. [16] studied the temperature effect on the ultraviolet aging of asphalt. The results indicated that the UV aging temperature was ignored under $50^{\circ} \mathrm{C}$. Zhang et al. [17] studied the ultraviolet aging properties of modified asphalt of three inorganic nanoparticles (nano- $\mathrm{SiO}_{2}$, nano- $\mathrm{TiO}_{2}$, and nano$\mathrm{ZnO}$ ). Their results showed that the nanoparticles (nano$\mathrm{ZnO}$ ) asphalt had the best UV aging resistance.

However, researches mainly focused on analyzing the aging of bitumen. There have been few reports to correlate the change of the amount of the filler with the UV aging of the bitumen, and the role and effect of the filler in bitumen are also ambiguous in the UV aging.

In this paper, UV radiation was used to simulate photooxidation aging of the asphalt mortar. FTIR, GPC, and DSR were then adopted to characterize the chemical structure, the molecular size distribution, and rheology of the asphalt mortar.

\section{Experimental}

2.1. Materials. The base asphalt SK-90 and its SBS-modified asphalt used in this paper were provided by Guochuang Asphalt Co. Ltd. (Shaanxi province, China). These main physical properties of this used asphalt are shown in Table 1. The mineral powder was sieved through $0.075 \mathrm{~mm}$, the specific surface area was $3.834 \mathrm{~m}^{2} / \mathrm{g}$, the average grain diameter was $6.510 \mu \mathrm{m}$, and the particle distribution was presented in Table 2.

2.2. Preparation of the Asphalt Mastics. According to the relevant research results [6-9], the mass ratios of the mineral powder to base asphalt (F/A) were selected as $0,1.0,1.2$, and 1.4. However, the SBS-modified asphalt is $0,0.8,1.0$, and 1.2.
Firstly, mineral powder was placed in an oven at $140^{\circ} \mathrm{C}$ for $4 \mathrm{~h}$, and two types of bitumen were heated to $140^{\circ} \mathrm{C}$. Secondly, in order to prevent the filler particles from agglomerating and to allow for uniform dispersion in the bitumen, mineral powder was added to the asphalt in a certain proportion. The mixture was blended at $1000 \mathrm{r} / \mathrm{min}$ to ensure the uniform dispersion of filler. Thirdly, the total mass of the sample was controlled to ensure that the film thickness was approximately $2 \mathrm{~mm}$. The sample plate was placed in a constant temperature oven by making full use of the mortar liquidity to keep the sample plate level. Finally, the sample plate was cooled at room temperature and placed in the UV environment oven. The process of the whole experiment is shown in Figures 1(a)$1(d)$.

\subsection{Methods}

2.3.1. Ultraviolet Aging Procedure. In this paper, the UV aging environment oven was designed according to the needs of experiment. The distance of these two $1000 \mathrm{~W}$ high-voltage mercury lamp was $40 \mathrm{~cm}$ and the UV aging time was $10 \mathrm{~d}$. The average UV density on sample surface is about $260 \mathrm{~W} / \mathrm{m}^{2}$. In order to prevent the asphalt mortar from thermal aging and maintain it at $35^{\circ} \mathrm{C}$ in the UV aging oven, the $200 \mathrm{~W}$ axial flow blower was used to supply sufficient cold air and the $100 \mathrm{~W}$ exhaust fan in the top of the oven was used to discharge warm air.

2.3.2. Fourier Transform Infrared. In this paper, changes in functional groups of mortar before and after UV aging were conducted with ATR-FTIR (is50, Nicolet, USA). The scan ranges from $600 \mathrm{~cm}^{-1}$ to $4000 \mathrm{~cm}^{-1}$ at a resolution of $4 \mathrm{~cm}^{-1}$.

Carbonyl group $\mathrm{C}=\mathrm{O}$ and sulfoxide group $\mathrm{S}=\mathrm{O}$ as well as the butadiene double bonds $\mathrm{C}=\mathrm{C}$ in the SBS-modified asphalt were monitored to characterize the UV aging degree of asphalt mastic $[18,19]$. Among them, the $1600 \mathrm{~cm}^{-1}$ peak is caused by the carbonyl groups $\mathrm{C}=\mathrm{O}$ and conjugated double bonds $\mathrm{C}=\mathrm{C}$ (benzene skeleton) stretching vibration [20]. The carbonyl index, sulfoxide index, and butadiene double bonds index are calculated by the area of their bands to evaluate the UV aging degree by following formulas (1) (3), respectively [21-23]:

$$
\begin{aligned}
& \mathrm{I}_{\mathrm{C}=\mathrm{O}} \\
& =\frac{\text { Area of carbonyle band centered around } 1600 \mathrm{~cm}^{-1}}{\sum \text { Area of spectral bands between } 2000 \text { and } 600 \mathrm{~cm}^{-1}}, \\
& \mathrm{I}_{\mathrm{SBS}} \\
& =\frac{\text { Area of butadiene centered around } 966 \mathrm{~cm}^{-1}}{\sum \text { Area of spectral bands between } 2000 \text { and } 600 \mathrm{~cm}^{-1}}, \\
& \mathrm{I}_{\mathrm{S}=\mathrm{O}} \\
& =\frac{\text { Area of sulfoxide band centered around } 1030 \mathrm{~cm}^{-1}}{\sum \text { Area of spectral bands between } 2000 \text { and } 600 \mathrm{~cm}^{-1}} .
\end{aligned}
$$

2.3.3. Gel Permeation Chromatography. The PL-GPC50 instrument (UK Polymer Laboratories Company) was used 


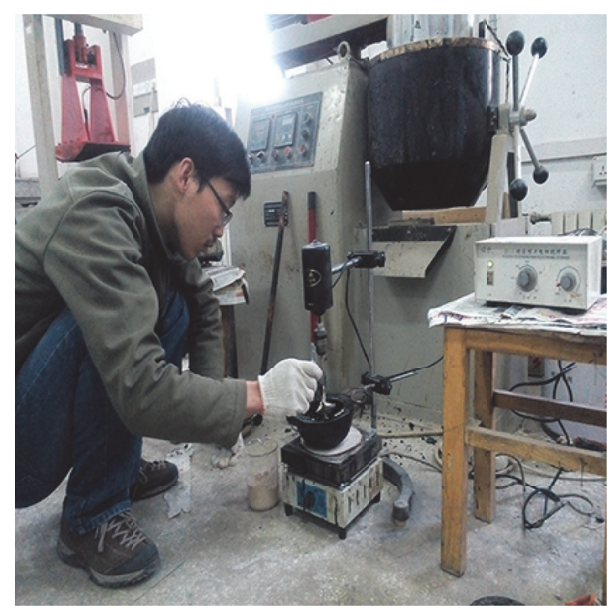

(a) Mortar production

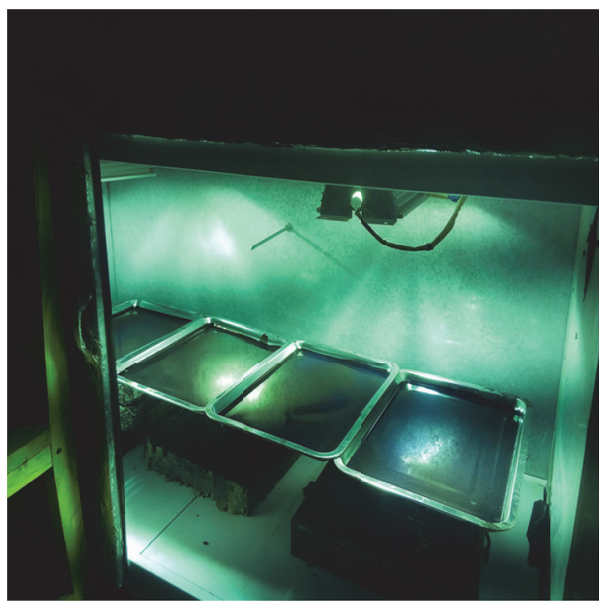

(d) Mortar UV aging

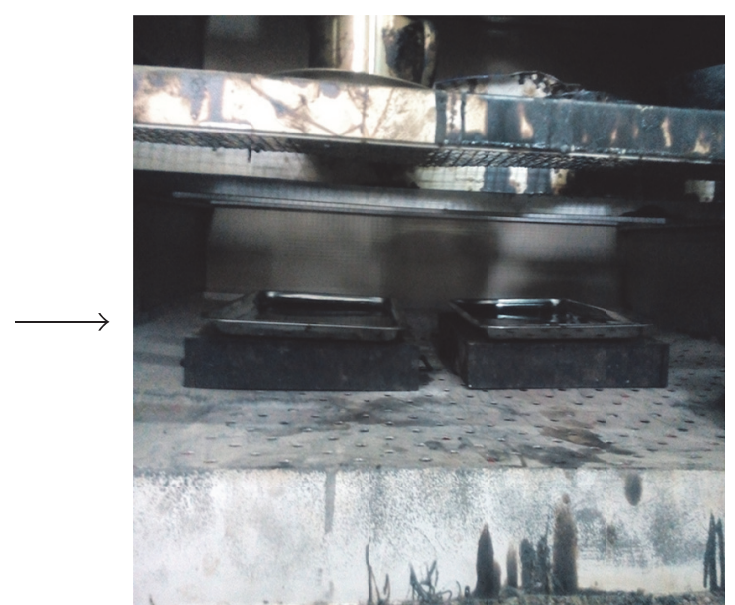

(b) Mortar leveling itself

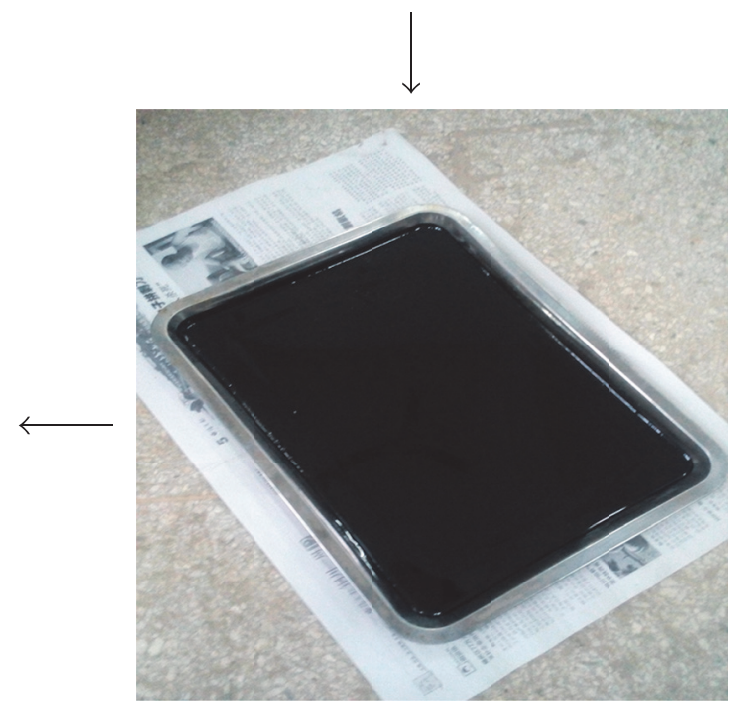

(c) Mortar cooling

FIGURE 1: The prepared process of the asphalt mortar.

to analyze the molecular size distribution of asphalt mortar before and after UV aging. The detector was the differential refractive index meter. The GPC columns used were PLgel $5 \mu \mathrm{m}$ Mixed-C $(7.5 \mathrm{~mm} \times 300 \mathrm{~mm})$. The testing temperature was $40^{\circ} \mathrm{C}$. Tetrahydrofuran (THF) was selected for mobile phase and the flow rate was $1 \mathrm{~mL} / \mathrm{min}$. The concentration of the sample was $2 \mathrm{mg} / \mathrm{mL}$.

2.3.4. Dynamic Shear Rheology Test. In this paper, the dynamic shear rheometer (Bohlin CVO, Malvern Instruments Ltd., UK) was applied to investigate the rheological properties of these asphalt mastics before and after UV aging. Under the constant strain controlled at $10 \mathrm{rad} / \mathrm{s}$, the parallel plates of $25 \mathrm{~mm}$ diameter with a gap width of $1 \mathrm{~mm}$ were used to estimate the rut factor $\left(G^{*} / \sin \delta\right)$ at $40^{\circ} \mathrm{C}$, and the parallel plates of $8 \mathrm{~mm}$ diameter with a gap width of $2 \mathrm{~mm}$ were used to measure the fatigue factor $\left(G^{*} \cdot \sin \delta\right)$ at $25^{\circ} \mathrm{C}[24]$. Besides, the fatigue factor aging index (FAI) and the rut factor aging index (RAI) were developed to evaluate the effect of aging on the fatigue ability resistance and the permanent deformation resistance of asphalt mortar [25], which could be calculated as with following equations

$$
\begin{aligned}
\text { FAI } & =\frac{\left(G^{*} \cdot \sin \delta\right)_{\text {After UV ageing }}}{\left(G^{*} \cdot \sin \delta\right)_{\text {Unaged }}} \\
\text { RAI } & =\frac{\left(G^{*} / \sin \delta\right)_{\text {After UV ageing }}}{\left(G^{*} / \sin \delta\right)_{\text {unaged }}}
\end{aligned}
$$

where $\left(G^{*} / \sin \delta\right)$ is rut factor, $\left(G^{*} \cdot \sin \delta\right)$ is fatigue factor, $G^{*}$ is complex modulus, and $\delta$ is phase angle.

\section{Results and Discussions}

3.1. Effect of the Filler on the Chemical Structure of Asphalt after UV Aging. Figures 2 and 3 show the chemical changes 


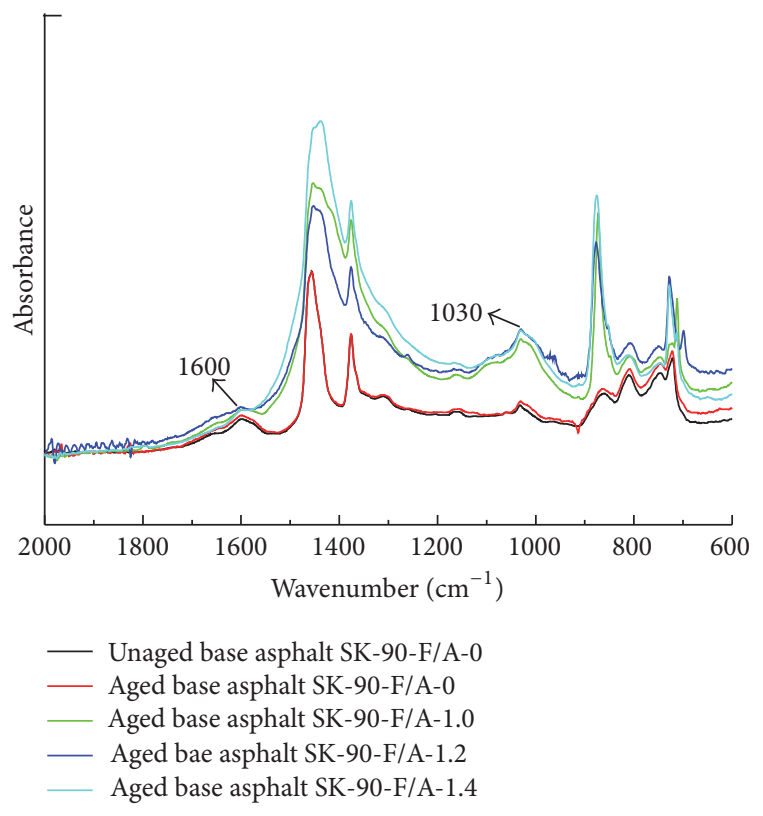

FIGURE 2: FTIR spectra of base asphalt mortar.

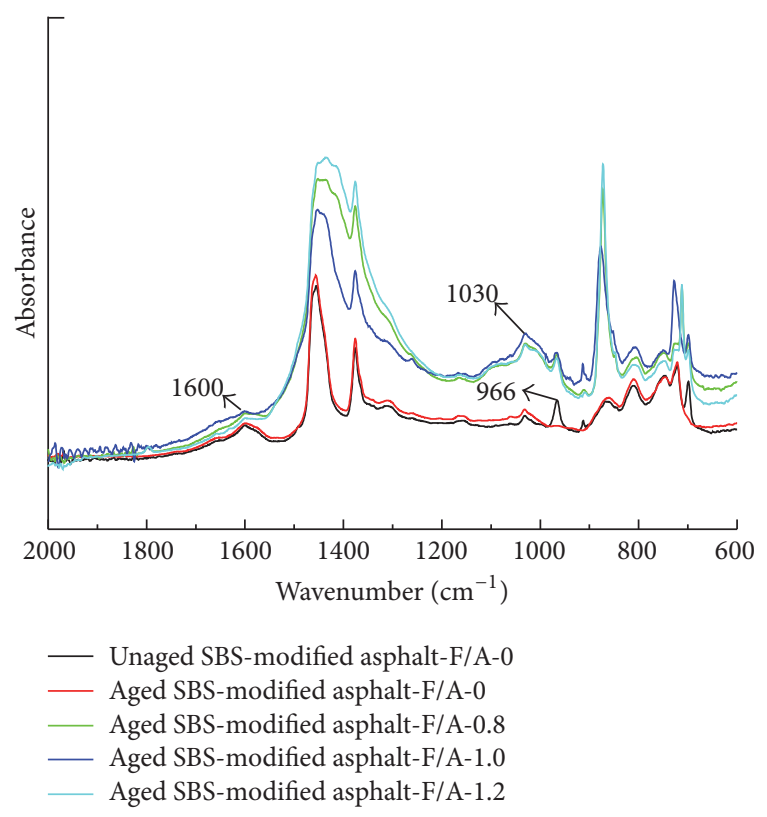

FIGURE 3: FTIR spectra of SBS-modified asphalt mortar.

of base asphalt mortar and SBS-modified asphalt mortar, respectively. The unique characteristic peaks at $966 \mathrm{~cm}^{-1}$ in SBS-modified asphalt mortar can be seen. These figures also show that the interaction of the asphalt-filler mainly maintains the characteristic peak of the asphalt. This may happen because of the physical adsorption action, which is consistent with the results of Tan and Guo [3].

Tables 3 and 4 give more detailed information about those changes. In the UV aging process of modified asphalt mortar, these indices of carbonyl group and sulfoxide group asphalt
TABLE 3: $\mathrm{I}_{\mathrm{C}=\mathrm{O}}$ and $\mathrm{I}_{\mathrm{S}=\mathrm{O}}$ changes of base asphalt mortar after UV aging.

\begin{tabular}{lcccc}
\hline \multirow{2}{*}{ Aging index } & \multicolumn{4}{c}{ Samples } \\
& 0 & 1.0 & 1.2 & 1.4 \\
\hline $\mathrm{I}_{\mathrm{C}=\mathrm{O}}$ & 0.06872 & 0.06308 & 0.04021 & 0.05766 \\
$\mathrm{I}_{\mathrm{S}=\mathrm{O}}$ & 0.06998 & 0.06377 & 0.06037 & 0.06727 \\
\hline
\end{tabular}

TABLE 4: $\mathrm{I}_{\mathrm{C}=\mathrm{O}}, \mathrm{I}_{\mathrm{S}=\mathrm{O}}$, and $\mathrm{I}_{\mathrm{SBS}}$ changes of SBS-modified asphalt mortar after UV aging.

\begin{tabular}{lcccc}
\hline \multirow{2}{*}{ Aging index } & \multicolumn{4}{c}{ Samples } \\
& 0 & 0.8 & 1.0 & 1.2 \\
\hline $\mathrm{I}_{\mathrm{C}=\mathrm{O}}$ & 0.06792 & 0.06037 & 0.05806 & 0.06595 \\
$\mathrm{I}_{\mathrm{S}=\mathrm{O}}$ & 0.06971 & 0.06578 & 0.06440 & 0.06712 \\
$\mathrm{I}_{\mathrm{SBS}}$ & 0.00748 & 0.00769 & 0.00767 & 0.00754 \\
\hline
\end{tabular}

mortar are less than the corresponding index of asphalt. For base asphalt mortar, the drop in the index of the carbonyl group is, at most, $41.49 \%$, whereas the drop of the index of sulfoxide group is, at most, $13.73 \%$. For SBS-modified asphalt mortar, the drop in the index of the carbonyl group is, at most, $14.52 \%$, whereas the drop of the index of sulfoxide group is, at most, $7.62 \%$. With the addition of the filler, the index of butadiene double bonds firstly increases and then decreases. The butadiene group changes by $2.42 \%$, indicating that the degree of degradation of the SBS modifier goes from slight to severe. This may be explained as follows: with an increasing amount of mineral powder, the oil content in the bitumen begins to decrease, to reduce the swelling effect of the SBS modifier, and to lead the SBS modifier to increase the degree of degradation in the UV radiations.

By changing group indices, the functional group index of the carbonyl group was the most significant. Therefore, the lightest UV aging degree of matrix asphalt mortar occurs for a mass ratio of 1.2 through the change of the carbonyl group, and for SBS-modified asphalt mortar, the lightest UV aging degree occurs at 1.0 through the change of the carbonyl functions and butadiene double bonds.

3.2. Effects of the Filler on the Molecular Structure of the Modified Asphalt after UV Aging. As shown in Figure 4, after UV aging, the molecular weight distribution curve of the SBS modifier in SBS-modified asphalt moves towards the direction of the small molecular weight. This result indicates that the SBS modifier shows degradation. When the mass ratio of the filler asphalt is less than 1.0, the molecular weight distribution curve of the SBS-modified moves gradually to the right, indicating that the degradation degree of the SBS modifier decreases. However, the molecular weight distribution curve of the SBS-modified F/A-1.2 substantially coincides with the modified asphalt. This result could be attributed to the decrease of the oil components, which reduces the swelling of the SBS modifier. Under UV radiation, the polymer can easily reach the excited state and react with oxygen. 


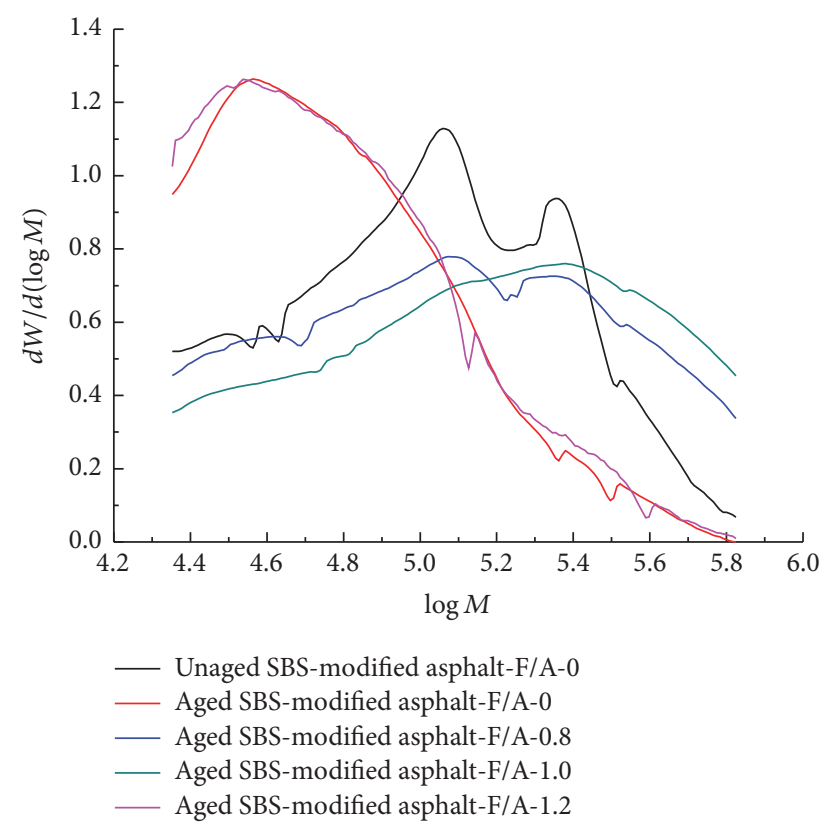

FIGURE 4: The molecular weight distribution of SBS modifier in modified asphalt mortar.

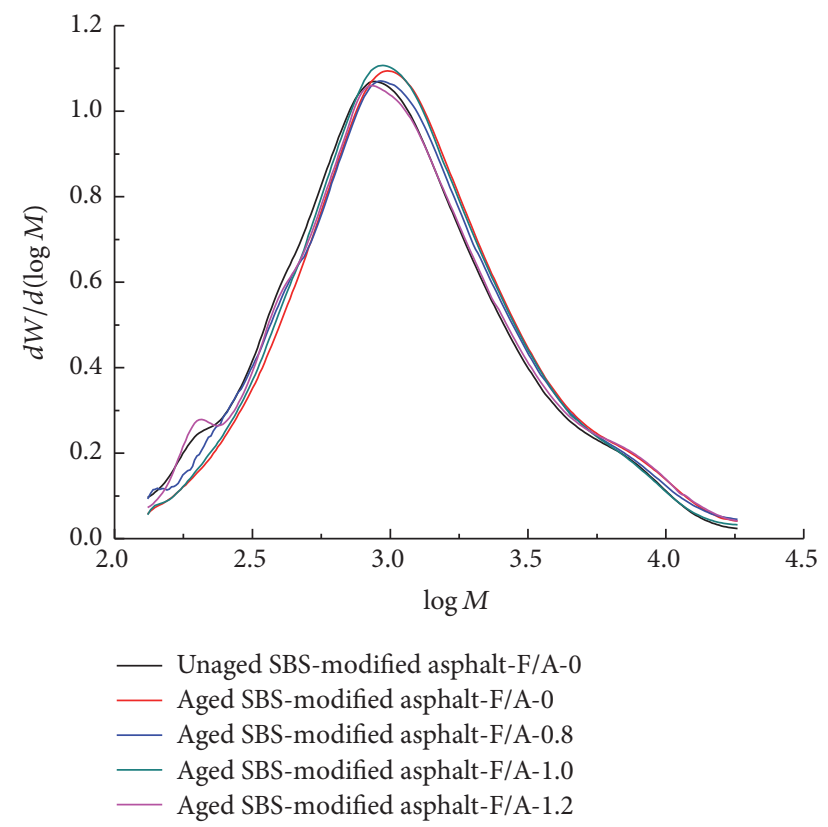

FIGURE 5: The molecular weight distribution of base asphalt in modified asphalt mortar.

As shown in Figure 5, with the increasing content of the filler, the molecular weight distribution curve of the base bitumen phase moves gradually to the left, indicating that the content of the large molecular weight decreases and that the ultraviolet aging degree of the asphalt phase has gradually weakened.

In the GPC, the outflow of the weight of $10 \%$ is defined as large molecular components, and the weight of $90 \%$ is

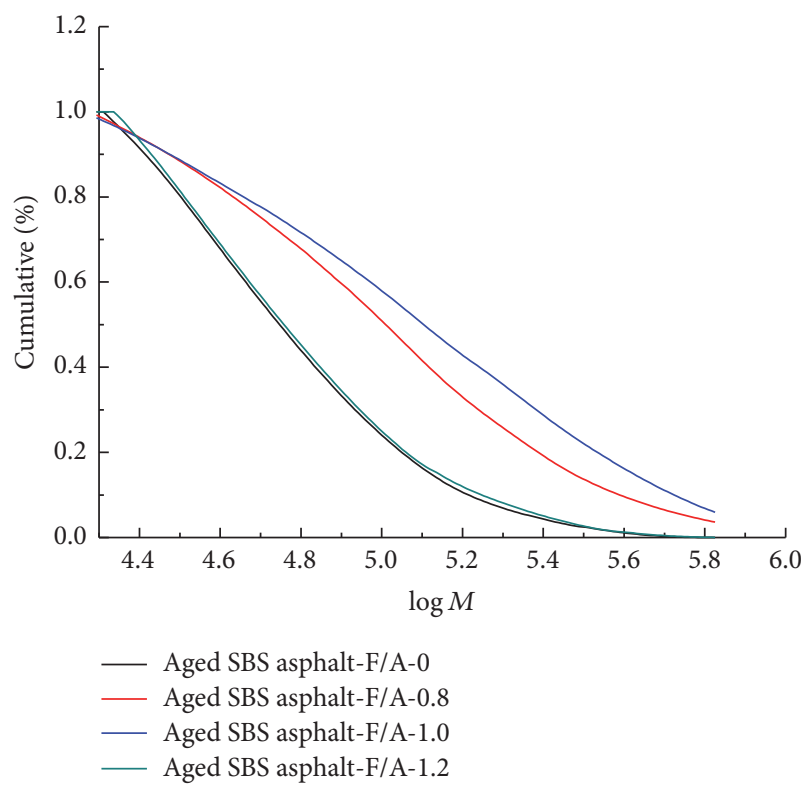

FIGURE 6: The molecular weight content of the modifier phase in the modified asphalt mortar.

TABLE 5: The average molecular weights of the modifier after UV aging.

\begin{tabular}{lcccc}
\hline Molecular weight & $M_{n}$ & $M_{w}$ & $M_{p}$ & $M_{w} / M_{n}$ \\
\hline F/A-0.0 & 49076 & 80769 & 36574 & 1.64 \\
F/A-0.8 & 76755 & 212613 & 119213 & 2.77 \\
F/A-1.0 & 91315 & 279719 & 239426 & 3.06 \\
F/A-1.2 & 50633 & 84138 & 34509 & 1.66 \\
\hline
\end{tabular}

defined as small molecular components. In this paper, effects of mineral powder on the molecular weight distribution of the modifier and the asphalt phase after UV aging were described quantitatively by the value of peak broadening $R$ (10\%, 90\%).

According to Figure 6, the values of the modifier phase are $6.30,12.90,17.58$, and 6.55 . The value first increases and then decreases. This trend indicates that the aging degree of the modifier changes from slight into severe and that the value of the modifier is increased 2.05 times, 2.83 times, and 1.03 times compared to the value of the modifier. The results above imply that mineral powder has a great influence on the interaction of the modifier and base bitumen. The more the amount of mineral powder increases, the more obvious this interference is. According to Figure 7, the values of the asphalt phase are $13.40,10.84,10.83$, and 11.71 . The value is gradually decreased at first and then increases. The values of the base asphalt in modified asphalt mastic are 0.93 times, 0.92 times, and 1.14 times higher than the values of the base asphalt.

As shown in Tables 5 and 6, the filler in the modifier mastic has a different influence on the SBS modifier and base asphalt. The average molecular weight of the asphalt phase is no longer obvious. The weight-average molecular weight $\left(M_{w}\right)$ of the SBS modifier is most obvious, with the largest decline being $71.12 \%$, indicating that $M_{w}$ of the SBS 


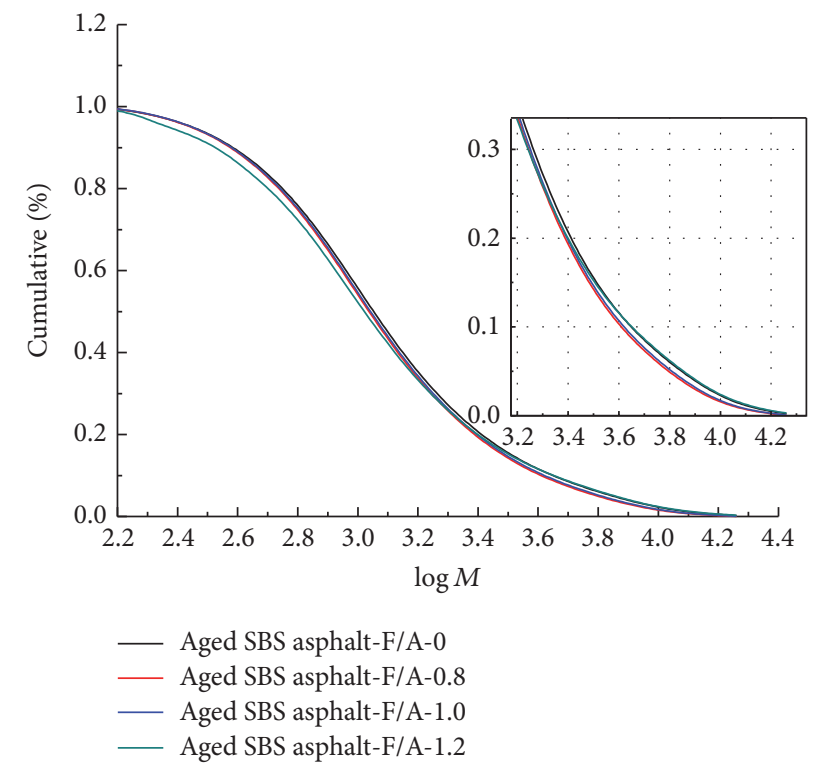

FIGURE 7: The molecular weight content of the bitumen phase in the modified asphalt mortar.

TABLE 6: The average molecular weights of the base asphalt after UV aging.

\begin{tabular}{lcccc}
\hline Molecular weight & $M_{n}$ & $M_{w}$ & $M_{p}$ & $M_{w} / M_{n}$ \\
\hline F/A-0.0 & 814 & 1956 & 977 & 2.40 \\
F/A-0.8 & 764 & 1840 & 940 & 2.41 \\
F/A-1.0 & 761 & 1860 & 922 & 2.44 \\
F/A-1.2 & 759 & 1939 & 957 & 2.55 \\
\hline
\end{tabular}

modifier is evaluated as the aging extent of the modifier. The distribution coefficient is characterized by the distribution width of the molecular weight, which is described using $M_{w} / M_{n}$ [25]. The larger the distribution coefficient is, the wider the molecular weight distribution is, namely, the less the molecule is concentrated in a certain interval. If the change interval of the component of the state of asphalt aggregate is coincident with the interval of the phase change of the molecular weight, the properties of the asphalt will change dramatically [26, 27]. For the SBS-modified asphalt mortar, the change of the SBS modifier has a great influence on its performance [28]. These relationships of the molecular weight distribution coefficient $\left(M_{w} / M_{n}\right)$ of the modifier are F/A-1.0 > F/A-0.8 > F/A-1.2 > F/A-0. Considering the above order, F/A-1.0 has the most stable macroscopic properties after UV aging.

3.3. Effect of the Filler on the Molecular Structure of Base Asphalt after UV Aging. As shown in Figure 8, after UV aging, there are obvious changes in the molecular weight in base asphalt mortar. Additionally the large molecular weight increase significantly, especially the molecular weight ranging from $10^{4.0}$ to $10^{4.5}$. This result indicates that polymerization

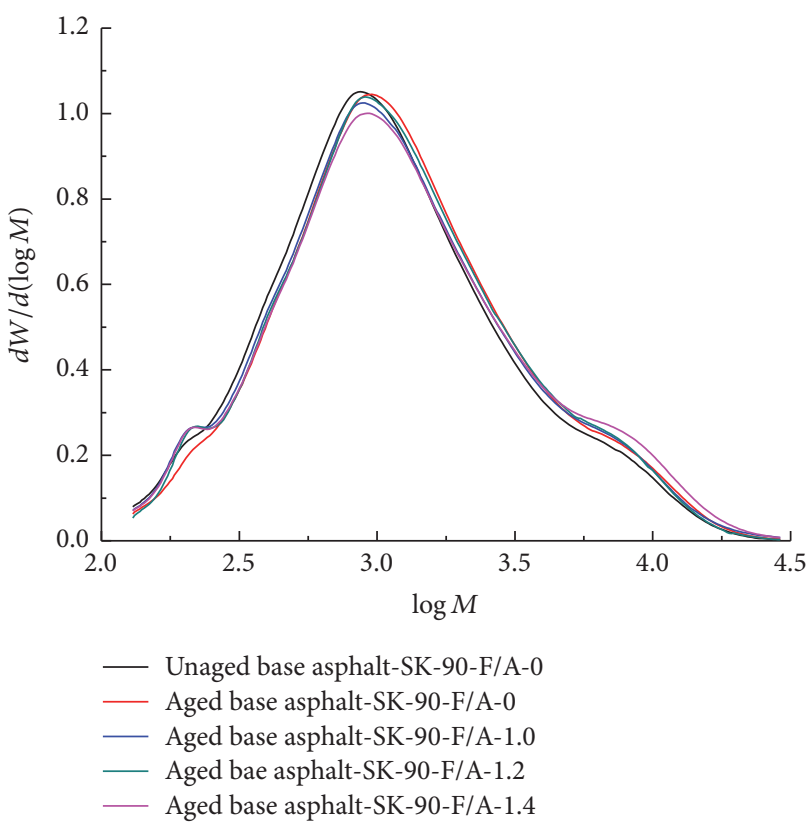

FIgURE 8: The molecular weight distribution of asphalt mortar.

occurs for asphalt mortar. Compared with the UV aging of the bitumen, the molecular weight distribution curve of asphalt mortar gradually moves to the left, which shows that adding mineral powder decreases the UV aging speed of the bitumen. It can be also seen from Figure 8 that the UV aging process of the asphalt mortar generates small molecular substances and that this may be because the components of the bitumen induce more side-chains breaks after UV aging. All the above results imply that the UV aging process of the asphalt mortar happens to side-chain breaks and polymerization at the same time. When too little or too much mineral powder is mixed with bitumen, the polymerization reaction is more significant. However, when adding the proper content of mineral powder, two types of reactions should prominently occur. As shown in Figure 9, the relationship of the large molecular weight of asphalt mortar is F/A-1.4 > F/A-0 > F/A-1.0 > F/A-1.2.

According to Table 7, the changing extent of $M_{n}$ is $13.28 \%$. Otherwise, the changing range of $M_{w}$ is only $1.84 \%$, and it firstly decreases and then increases. The number-average molecular weight $\left(M_{n}\right)$ is greater than $M_{w}$. It might be explained that these light components are absorbed by the certain mineral powder and that, by slowing the speed of the small molecules polymerized into large molecule, the aging degree is more lighter. However, when adding excessive fillers, the aging degree is more serious. Because the asphalt mortar tension is enhanced and causes the free precipitation of one part of mineral powder, the more the asphalt is exposed, the more serious the aging degree is. Therefore, $M_{n}$ is used to evaluate the UV aging degree of the base asphalt mortar. The relationship of the molecular weight distribution coefficient of asphalt mortar and bitumen is F/A-1.2 > F/A-1.0 $>$ F/A-1.4 > F/A-0. Considering the above order, F/A-1.2 has the most stable macroscopic properties after UV aging. 
TABLE 7: The average molecular weights of asphalt mortar after UV aging.

\begin{tabular}{lcccc}
\hline Molecular weight & $M_{n}$ & $M_{w}$ & $M_{p}$ & $M_{w} / M_{n}$ \\
\hline F/A-0.0 & 821 & 2068 & 958 & 2.52 \\
F/A-1.0 & 761 & 2057 & 887 & 2.70 \\
F/A-1.2 & 712 & 2030 & 922 & 2.85 \\
F/A-1.4 & 795 & 2120 & 934 & 2.66 \\
\hline
\end{tabular}

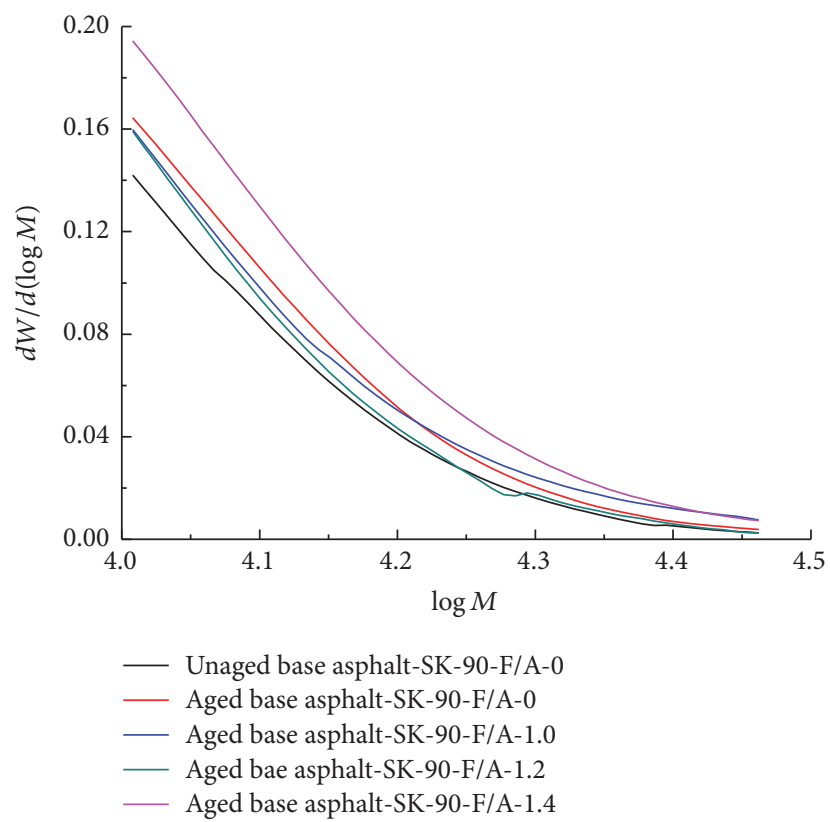

Figure 9: The large molecular weight distribution.

3.4. Effect of the Mineral Powder on UV Aging Rheological Properties of Bitumen. As shown in Figures 10 and 11, FAI and RAI are lower for the SBS-modified asphalt mortar ranging from 0.8 to 1.0 and the base asphalt mortar ranging from 1.0 to 1.2. These great FAI and RAI indicate these serious UV reactions [24]. It shows that adding the mineral powder to asphalt reduces the extent of UV aging. Therefore, this is consistent with the conclusion of GPC and FTIR. In particular, the fatigue factor aging index is the most significant, among which the modified asphalt mortar has the largest decline in $37.49 \%$ and the matrix asphalt mortar declines in $41.18 \%$. It also shows that the UV aging has great influence on the fatigue performance of asphalt mortar.

\section{Conclusions}

In this paper, effects of mineral powder on the UV aging properties of the base asphalt and SBS-modified asphalt were investigated. The chemical structure, molecular structure, and dynamic rheological behaviors were researched. The following conclusions can be drawn:

(1) By FTIR analysis, the UV aging resistance of the SBS-modified asphalt mortar is superior to the base

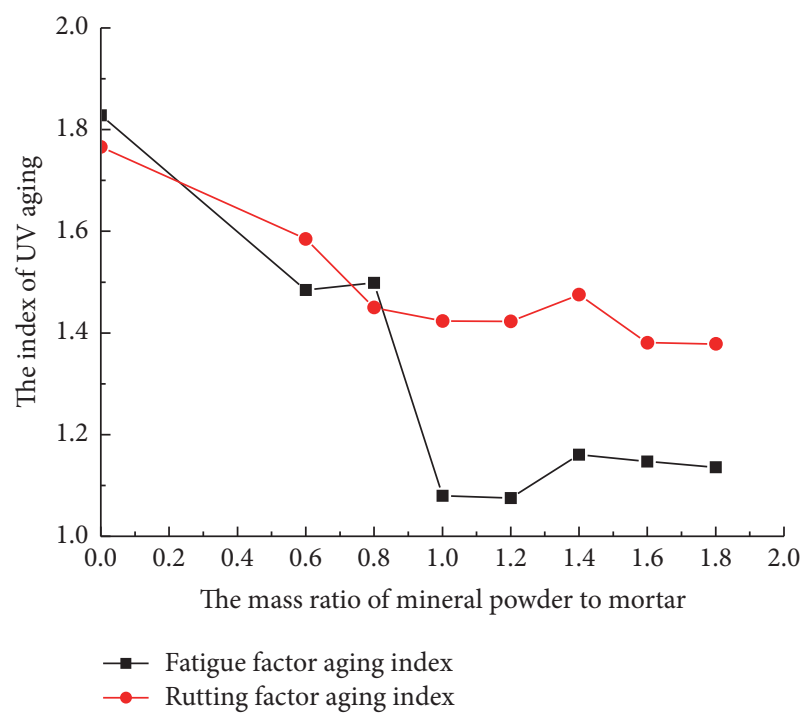

FIGURE 10: The aging index of base asphalt mortar.

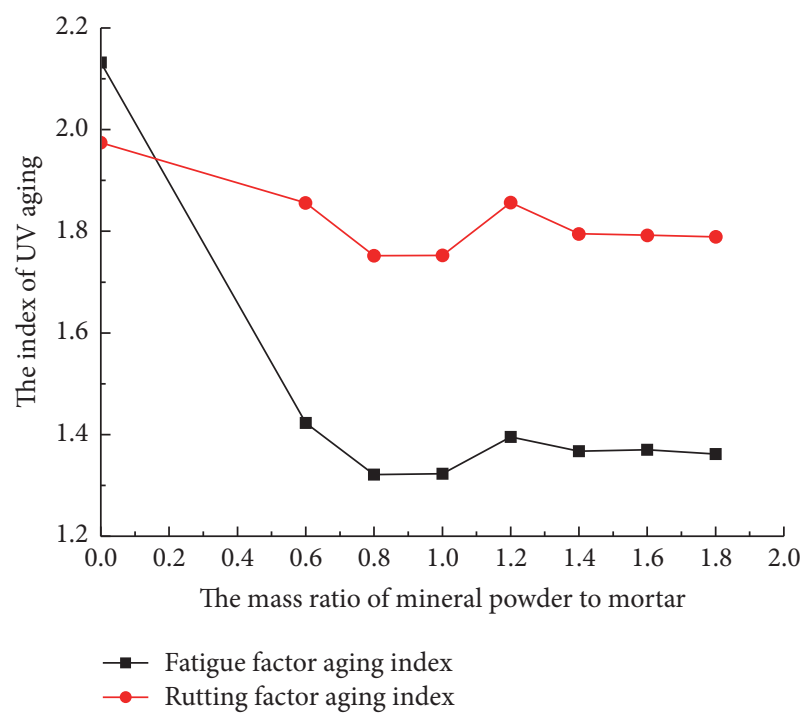

FIGURE 11: The aging index of modified asphalt mortar.

asphalt mortar. After UV aging, the variation width of the carbonyl functional group index in the SBSmodified asphalt mortar is the largest, with a maximum amplitude of $14.52 \%$, while the unique butadiene index decreases $2.42 \%$ at most. The change range of the carbonyl group index in base asphalt mortar has the largest drop of $41.49 \%$, so the carbonyl index is used to evaluate the UV aging degree of the base asphalt mortar.

(2) By GPC analysis, the UV aging of SBS-modified asphalt mortar is composed of the SBS modifier and asphalt, among which the average molecular weight $\left(M_{w}\right)$ of the modifier has the most significant changes, with a maximum amplitude of $71.12 \%$. Therefore, $M_{w}$ is used to evaluate the degree of the modifier asphalt mortar. For base asphalt mortar, the average 
molecular weight $\left(M_{n}\right)$ has the most obvious changes, with a maximum rate of $13.28 \%$. Therefore, $M_{n}$ is used to evaluate the degree of the base asphalt mortar. According to the molecular weight distribution index, these macroscopic properties are the most stable for the mineral powder to base asphalt ratio of F/A-1.2 and the mineral powder to SBS-modified asphalt ratio of F/A-1.0.

(3) By comparing the aging index of the fatigue and rutting factors of different asphalt mortars, the UV radiation has a great influence on the fatigue performance of asphalt mortar. The UV aging resistance of SBS-modified asphalt mortar is better than matrix asphalt mortar.

(4) The different amount of mineral powder could affect the different UV aging degrees of asphalt. Based on the changes of microstructure and macrorheological properties, modified asphalt mortar is best for a mass ratio of 1.0, and the best mass ratio for matrix asphalt mortar is 1.2 under UV conditions.

\section{Competing Interests}

The authors declare that they have no competing interests.

\section{Acknowledgments}

The authors are grateful for financial support from National Natural Science Foundation of China (Grant no. 51408480) and the West Science and Technology Project of the Department of Transportation, China (Grant no. 20113187721260).

\section{References}

[1] C. Davis and C. Castorena, "Implications of physico-chemical interactions in asphalt mastics on asphalt microstructure," Construction and Building Materials, vol. 94, pp. 83-89, 2015.

[2] H. Wang, I. Al-Qadi, A. Faheem, H. Bahia, S.-H. Yang, and G. Reinke, "Effect of mineral filler characteristics on asphalt mastic and mixture rutting potential," Journal of the Transportation Research Board, vol. 2208, pp. 33-39, 2011.

[3] Y. Q. Tan and M. Guo, "Using surface free energy method to study the cohesion and adhesion of asphalt mastic," Construction and Building Materials, vol. 47, pp. 254-260, 2013.

[4] F. Cardone, F. Frigio, G. Ferrotti, and F. Canestrari, "Influence of mineral fillers on the rheological response of polymer-modified bitumens and mastics," Journal of Traffic and Transportation Engineering, vol. 2, no. 6, pp. 373-381, 2015.

[5] W. Grabowski and J. Wilanowicz, "The structure of mineral fillers and their stiffening properties in filler-bitumen mastics," Materials and Structures, vol. 41, no. 4, pp. 793-804, 2008.

[6] Y. Q. Tan, Z. H. Li, X. Y. Zhang, and Z. J. Dong, "Research on high-and low-temperature properties of asphalt-mineral filler mastic," Journal of Materials in Civil Engineering, vol. 22, no. 8, pp. 811-819, 2010.

[7] RIOH, "Technical specifications for construction of highway asphalt pavement," Tech. Rep. JTG F40-2004, Research Institue of Highway Ministry of Transport, Beijing, China, 2004.
[8] B.-G. Wang, P. Li, Z.-Q. Zhang, and H.-W. Sun, "Influence of mineral powder on aging properties of asphalt mortar," Journal of Chang'an University (Natural Science Edition), vol. 27, no. 4, pp. 6-9, 2007 (Chinese).

[9] R. Brown, E. Dukatz, G. Huber, L. Michael, J. Scherocman, and R. Sines, "Performance of coarse-graded mixes at Westrack-premature rutting," Final Report FHWA-RD99-134, US Department of Transportation, Federal Highway Administration, Washington, DC, USA, 1998.

[10] Y. H. Ruan, R. R. Davison, and C. J. Glover, "The effect of long-term oxidation on the rheological properties of polymer modified asphalts," Fuel, vol. 82, no. 14, pp. 1763-1773, 2003.

[11] X. H. Lu and U. Isacsson, "Chemical and rheological evaluation of ageing properties of sbs polymer modified bitumens," Fuel, vol. 77, no. 9-10, pp. 961-972, 1998.

[12] K. W. Kim and J. L. Burati, "Use of GPC chromatograms to characterize aged asphalt cements," Journal of Materials in Civil Engineering, vol. 5, no. 1, pp. 41-52, 1993.

[13] H. I. Al-Abdul Wahhab, I. M. Asi, F. M. Ali, and I. A. Al-Dubabi, "Prediction of asphalt rheological properties using HP-GPC," Journal of Materials in Civil Engineering, vol. 11, no. 1, pp. 6-14, 1999.

[14] S. P. Wu, L. T. Mo, and Z. H. Lin, "Study on modified asphalt film-thickness and properties of modified asphalt for modified asphalt mixture," Joural of Wuhan University of Technology (Materials Science), vol. 24, pp. 51-54, 2004.

[15] F. Durrieu, F. Farcas, and V. Mouillet, "The influence of UV aging of a Styrene/Butadiene/Styrene modified bitumen: comparison between laboratory and on site aging," Fuel, vol. 86, no. 10-11, pp. 1446-1451, 2007.

[16] W. B. Zeng, S. P. Wu, J. Wen, and Z. Chen, "The temperature effects in aging index of asphalt during UV aging process," Construction and Building Materials, vol. 93, pp. 1125-1131, 2015.

[17] H. L. Zhang, C. Z. Zhu, J. Y. Yu, C. Shi, and D. Zhang, "Influence of surface modification on physical and ultraviolet aging resistance of bitumen containing inorganic nanoparticles," Construction and Building Materials, vol. 98, pp. 735-740, 2015.

[18] J. Lamontagne, P. Dumas, V. Mouillet, and J. Kister, "Comparison by Fourier transform infrared (FTIR) spectroscopy of different ageing techniques: application to road bitumens," Fuel, vol. 80, no. 4, pp. 483-488, 2001.

[19] S.-P. Wu, L. Pang, L.-T. Mo, Y.-C. Chen, and G.-J. Zhu, "Influence of aging on the evolution of structure, morphology and rheology of base and SBS modified bitumen," Construction and Building Materials, vol. 23, no. 2, pp. 1005-1010, 2009.

[20] X. Feng, F. Ye, and P. Huang, "Infrared spectrum analysis of carbonyl absorbance on asphalt aging," Journal of Building Materials, vol. 11, no. 3, pp. 375-378, 2008 (Chinese).

[21] M. R. Nivitha, E. Prasad, and J. M. Krishnan, "Ageing in modified bitumen using FTIR spectroscopy," International Journal of Pavement Engineering, vol. 17, no. 7, pp. 565-577, 2015.

[22] J. Y. Yu, L. Wang, X. Zeng, S. P. Wu, and B. Li, "Effect of montmorillonite on properties of styrene-butadiene-styrene copolymer modified bitumen," Polymer Engineering and Science, vol. 47, no. 9, pp. 1289-1295, 2007.

[23] M. R. Nivitha, E. Prasad, and J. M. Krishnan, "Ageing in modified asphalt using FTIR spectroscopy," International Journal of Pavement Engineering, vol. 17, no. 7, pp. 565-577, 2016. 
[24] R. E. Petersen, D. A. Anderson, and J. W. Button, Binder Characterization and Evaluation. Volume 3: Physical Characterization, SHRP-A-369, National Research Council, Washington, DC, USA, 1994.

[25] S.-J. Lee, J. Hu, H. Kim, S. N. Amirkhanian, and K.-D. Jeong, "Aging analysis of rubberized asphalt binders and mixes using gel permeation chromatography," Construction and Building Materials, vol. 25, no. 3, pp. 1485-1490, 2011.

[26] Z. Q. Zhang, D. L. Zhang, and J. A. Yuan, “The influence of the molecular weight and the state transition characteristic on the performance of asphalt," Journal of Xian Highway University, vol. 18, no. 3, pp. 207-211, 1998.

[27] F.-Q. Zeng, X.-M. Huang, and H.-J. Li, "Evaluation method of differential scanning calorimetry for asphalt performance," Journal of Traffic and Transportation Engineering, vol. 5, no. 4, pp. 37-42, 2005.

[28] L. Sun, Y. Y. Wang, and Y. M. Zhang, "Aging mechanism and effective recycling ratio of SBS modified asphalt," Construction and Building Materials, vol. 70, pp. 26-35, 2014. 

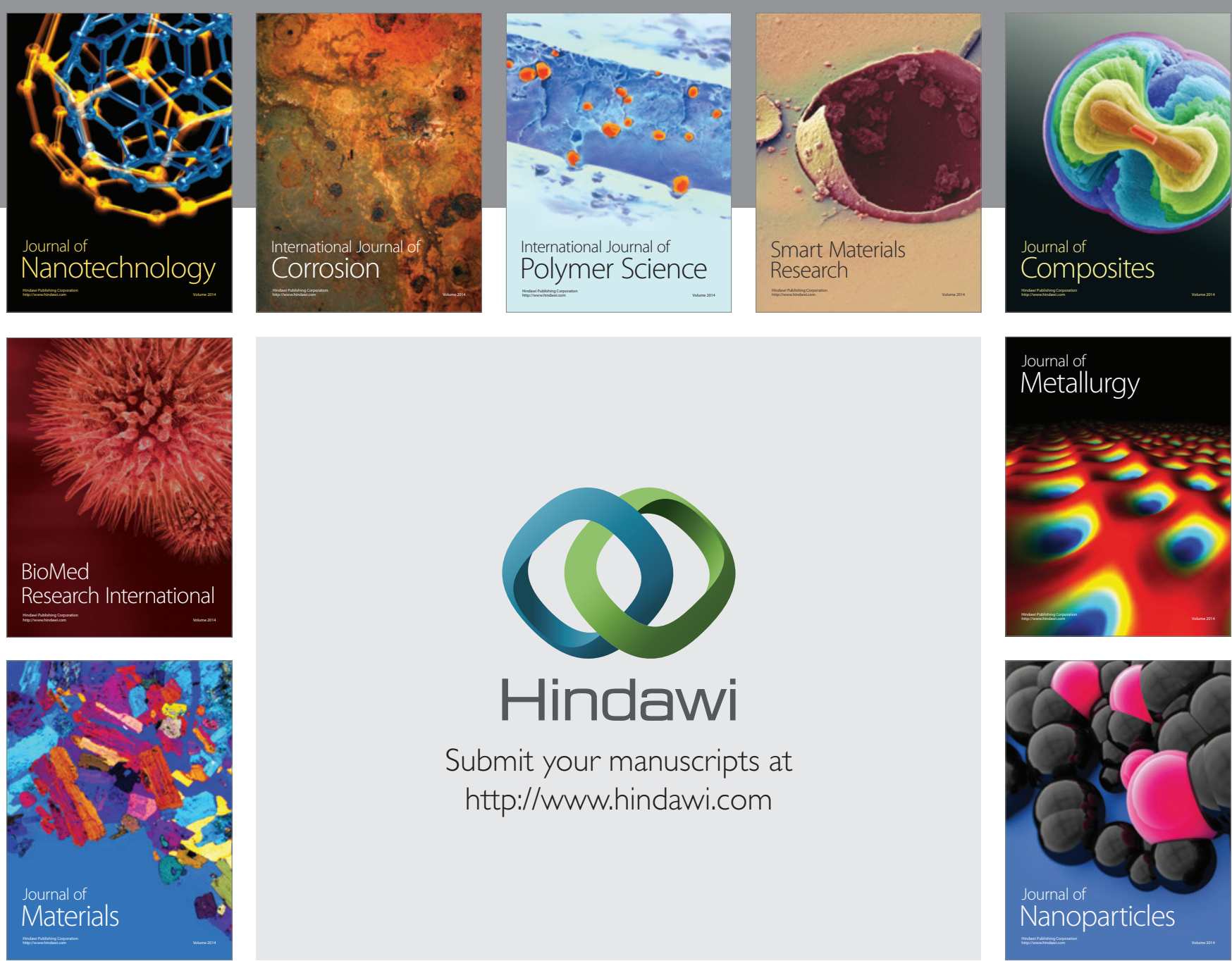

\section{Hindawi}

Submit your manuscripts at

http://www.hindawi.com

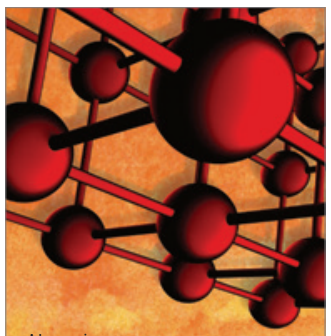

Materials Science and Engineering
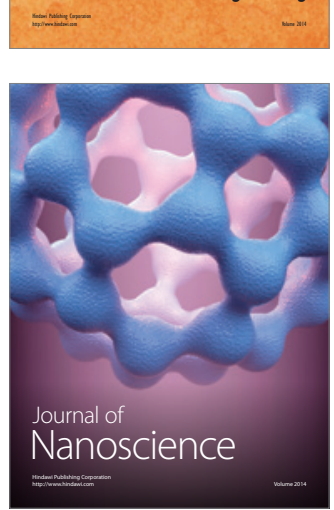
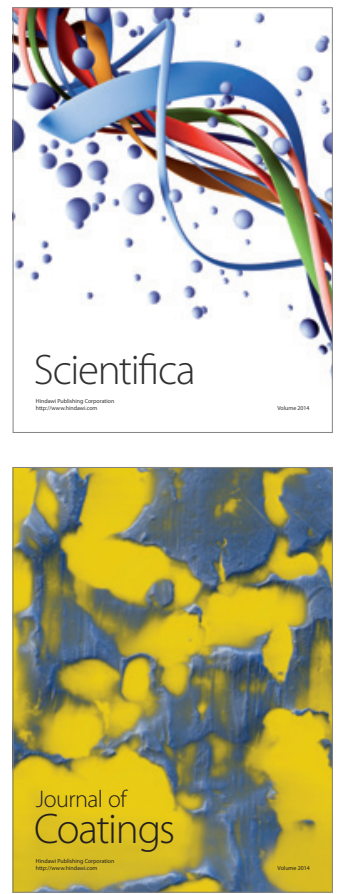
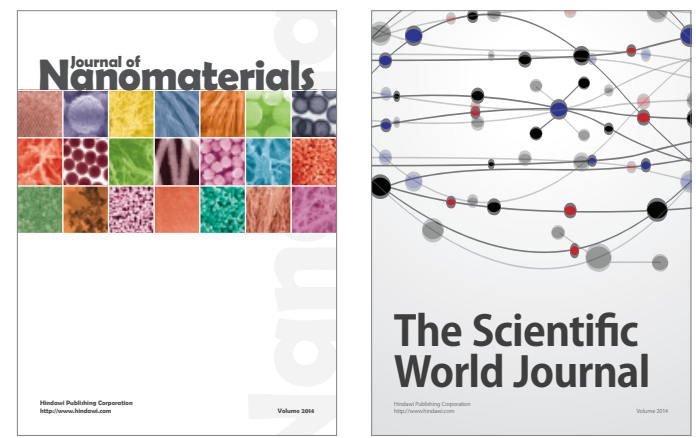

The Scientific World Journal
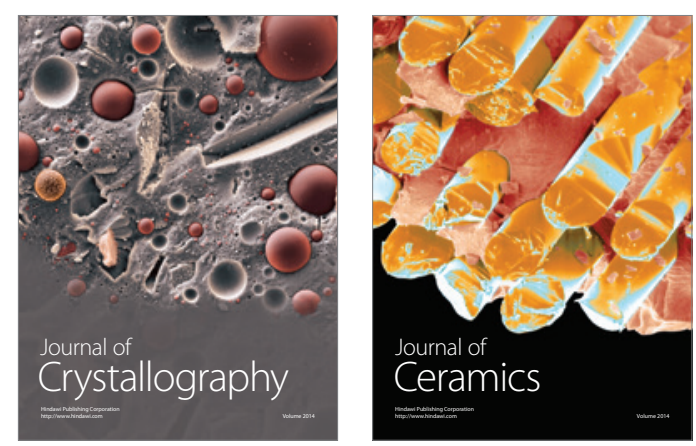
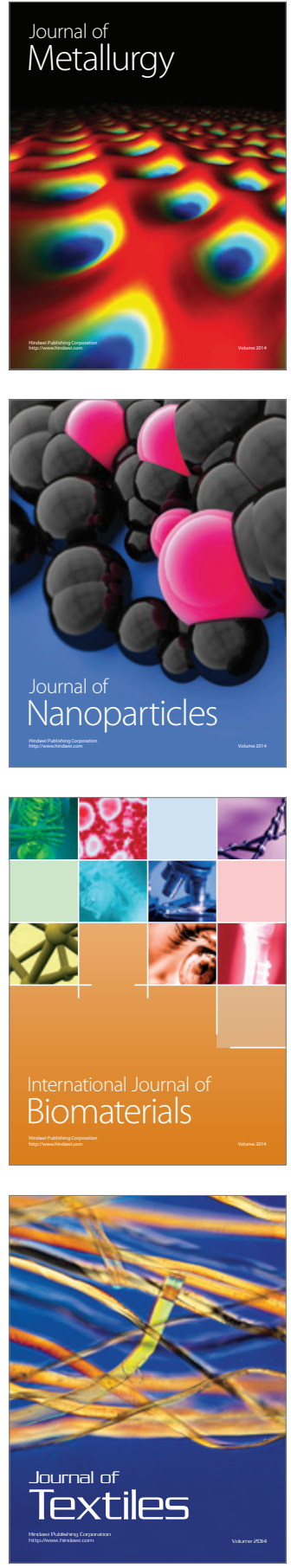